\title{
Генерация закрученных и векторных пучков в терагерцовом диапазоне
}

\author{
Ю.Ю. Чопорова ${ }^{1,2}$, Н.Д. Осинцева ${ }^{1,2, *}$, В.С. Павельев ${ }^{3,4}$, \\ К.Н. Тукмаков ${ }^{3,4}$, Б.А. Князев ${ }^{1,2}$ \\ ${ }^{1}$ Институт ядерной физики им. Г.И. Будкера СО РАН \\ ${ }^{2}$ Новосибирский государственный университет \\ ${ }^{3}$ Самарский национальный исследовательский университет им. академика С.П. Королева \\ ${ }^{4}$ Институт систем обработки изображений РАН-ФНИЦ «Кристаллография и фотоника»РАН \\ *E-mail: natalyaosintseva@gmail.com
}

DOI: 10.31868/RFL2020.228-229

В последние годы значительно возрос интерес к пучкам, обладающим орбитальным угловым моментом (ОУМ), или «закрученным» пучкам. Благодаря превосходной стабильности передачи, бесселевы и закрученные пучки особенно полезны для использования в беспроводных коммуникационных системах. Известно, что комбинацию таких пучков, распространяющихся в свободном пространстве, можно использовать для создания мультиплексного коммуникационного канала передачи данных [1]. Такая возможность была продемонстрирована экспериментально в видимом [2], радиочастотном [3] и миллиметровом диапазонах. Можно предположить, что аналогичным образом можно создать и мультиплексные проводные коммуникационные системы, например плазмонные. В этом случае сигнал будет передаваться по цилиндрическим проводникам с помощью поверхностных плазмон-поляритонов (ППП) несущих ОУМ. В наших работах уже была продемонстрирована возможность генерации закрученных пучков в терагерцовом (ТГц) диапазоне, а также предложена схема создания «идеальных» векторных закрученных пучков для генерации ППП на цилиндрах [4].

В качестве источника монохроматического ТГц излучения использовался Новосибирский лазер на свободных электронах (НЛСЭ). Для создания пучков заданной моды мы использовали дифракционные оптические элементы (ДОЭ). Гауссов пучок НЛСЭ трансформировался в моды Эрмитта-Гаусса $(Э Г) ~(1,0)$ и $(0,1)[5]$ и Бесселя с топологическими зарядами $l= \pm 1, \pm 2$ [6]. В обоих случаях, генерации комбинированных закрученных и «идеальных» векторных закрученных пучков, использовалась схема Маха-Цендера (Рис. 1). Совмещение двух закрученных пучков дает их суперпозицию (Рис. 1 справа), что позволит передавать несколько сигналов на одной частоте.

Для генерации ППП, необходимо учитывать условие их возбуждения наличие поляризации ортогональной к поверхности. В случае цилиндрического провода, поляризация должна быть радиальной. Для получения таких пучков в каждом из плеч генерировались ЭГ пучки (ДОЭ , ДОЭ $_{2}$ на рис. 1). ДОЭ и поляризация были установлены ортогонально друг другу. В результате суперпозиции ЭГ пучков была получена мода Лагерра-Гаусса, освещавшая закручивающий элемент ДОЭз (врезка). Для обеспечения постоянного диаметра пучка вне зависимости от его топологического заряда использовалась кремниевая линза в качестве Фурье-преобразователя (ДОЭ схеме интерферометра). Экспериментально были получены «идеальные» векторные пучки с закрученностью - 1 . 


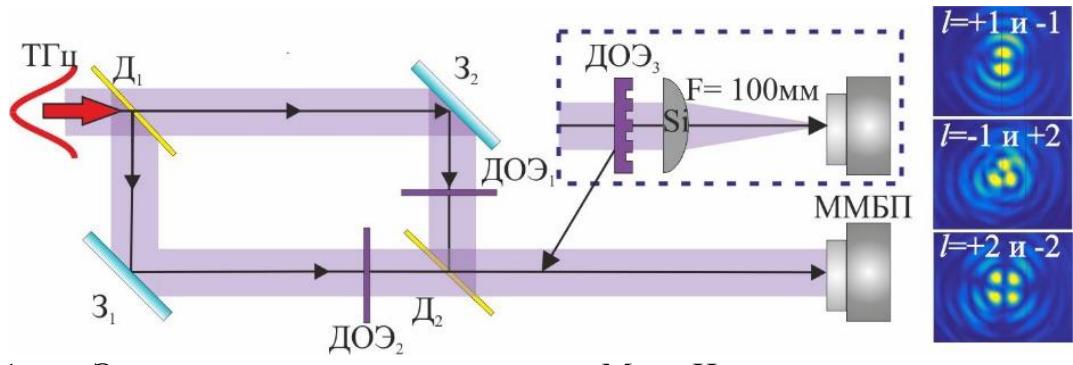

Рис. 1. Экспериментальная схема Маха-Цендера для генерации комбинированных закрученных и «идеальных» векторных закрученных пучков (врезка): Д 1 , Д2 - пленочные светоделители, $3_{1}, 3_{2}$-зеркала, ДОЭ ${ }_{1,2}, 3-$ ДОЭ для генерации пучков ЭГ и бесселевой моды с топологическими зарядами $l= \pm 1, \pm 2$. Справа: комбинированные закрученные пучки (эксперимент)

Работа выполнена при поддержке гранта РНФ (грант № 19-12-00103). Эксперименты выполнены в ИЯФ СО РАН с использованием оборудования ЦКП «СЦСТИ» на базе УНУ «Новосибирский ЛСЭ».

\section{Литература}

[1] А. А. Алмазов, и др., Оптический журнал 72(5), 45-54 (2005)

[2] M. Krenn, et al., New Journal of Physics 16(11), 113028 (2014).

[3] F. Tamburini, et al., New Journal of Physics 14(3), 033001 (2012)

[4] Б. А. Князев и др., Компьютерная оптика, 43 (6), 992-1000 (2019)

[5] A. N. Agafonov, et al., Applied Optics 54 12, 3635-3639 (2015).

[6] Yu. Yu. Choporova, et al., Physical Review A 96(2), 023846 (2017).

Научный руководитель - канд. физ.-мат. наук Ю.Ю. Чопорова 